\title{
Estética e simetria nas leis de Newton: uma análise de alguns livros didáticos usados na formação inicial de professores de Física
}

Flaviston Ferreira Pires ${ }^{1}$

Mestrando pelo Programa de Pós-Graduação em Ensino de Ciências

e Matemática - UNIFESP

José Alves da Silva ${ }^{1}$

Thaís Cyrino de Mello Forato ${ }^{1}$

Universidade Federal de São Paulo

Diadema - SP

\section{Resumo}

Levando-se em consideração uma concepção de educação voltada para a promoção do ser humano, este trabalho destaca a busca das bases estéticas e simétricas dos fenômenos nas leis de Newton e como ou se essas bases estão presentes em alguns livros didáticos de física utilizados em cursos de licenciatura na área, de modo a propor uma reflexão sobre suas possíveis implicações para o ensino das leis de Newton. Essas bases, de natureza epistemológica, relacionadas à homogeneidade e isotropia do espaço e à irreversibilidade do tempo, são fundamentais para que se compreendam os seus três princípios fundamentais: conservação da quantidade de movimento linear, angular e da energia. Para tanto, realizamos uma pesquisa historiográfica acerca de tais conceitos na obra de diferentes pensadores, buscando identificar pressupostos estéticos possivelmente utilizados na fundamentação dessas leis. Esses primeiros resultados foram utilizados em uma segunda etapa da pesquisa na proposição de instrumentos de análise sobre tais conteúdos nos livros didáticos. A seguir, foram analisados cinco livros utilizados na formação de professores de física. Constatamos que os livros não discutem as leis de Newton na perspectiva dos conceitos de estética e simetria, apresen-

\footnotetext{
+Aesthetics and symmetry in Newton's laws: an analysis of some textbooks used in physics initial teacher training

* Recebido: junho de 2018.

Aceito: abril de 2019.

${ }^{1}$ E-mails: ton.fpires@hotmail.com; josealves.unifesp@gmail.com; thaiscmf@gmail.com
} 
tando uma versão naturalizada, linear e de caráter enciclopédico dos conceitos físicos referentes às leis de Newton, bem diferente do que propõem os autores que discutem estética e simetria.

Palavras-chave: Estética; Simetria; Leis de Newton; Livros Didáticos; Formação Inicial de Professores.

\begin{abstract}
Taking into account a conception of education aimed at promoting the human being, this work highlights the search for the aesthetic and symmetrical bases of the phenomena in Newton's laws and how or if these bases are presents in some textbooks of physics used in courses of graduation in the area, aiming to propose a reflection on its possible implications for the teaching of Newton's laws. These bases, of epistemological nature, are related to isotropy and homogeneity of space and irreversibility of time, essential to comprehend three fundamental principles of physics: conservation of linear and rotational momentum and energy, which are involved in Newton's laws. Thus, we performed a historiographical research on the concepts of aesthetics and symmetry, aiming to identify the aesthetic assumptions used in the foundation of these laws. These results were used in a second stage of the research in the proposition of instruments of analysis on such contents in textbooks. Next, five books used in the physics teachers training were analyzed. From the highlight of this work, we aim to reveal that the books do not discuss the subject, presenting a naturalized, linear and encyclopedic version of physics concepts, quite different from what the authors who discuss aesthetics and symmetry propose.
\end{abstract}

Keywords: Aesthetic; Symmetry; Newton's Laws; Textbooks; Initial Teacher Training.

\title{
I. As nossas questões
}

A área de ensino de física tem feito trabalhos sistemáticos acerca de livros didáticos, especialmente aqueles direcionados à educação básica, sobretudo no ensino médio (MORAES, 2011; GARCIA, 2012; NASCIMENTO, 2011; PAGLIARINI, 2007; MEGID NETO; FRACALANZA, 2006). Juntamente com o Programa Nacional do livro Didático (PNLD), inegavelmente, essas pesquisas influenciaram positivamente a qualidade das obras (GARCIA, 2012). Entretanto, pouco pode ser dito de avanços no que se refere às pesquisas sobre livro didático no ensino superior, particularmente naqueles voltados às licenciaturas em física. 
Cabe salientar, desde já, que o livro, como todo instrumento didático, apresenta vantagens e riscos em seus usos. Por isso, não podemos menosprezar o apoio que o livro pode oferecer ao processo de ensino-aprendizagem, em especial na discussão dos conteúdos, em sua sequência e em sua forma. Entretanto, de acordo com Alice Lopes (1992), no contexto do uso do livro didático no aprendizado das ciências, este não atua como auxiliar do processo de ensino e aprendizagem, mas como modelo padrão, autoridade absoluta, critério último de verdade: parece modelar os professores. Martorano e Marcondes (2009, p. 342) defendem que é o livro utilizado, portanto, e não somente o currículo formativo, que parece condicionar a forma como o pensamento do professor em formação é estruturado, uma vez que ele "determina a maneira e a sequência da apresentação de qualquer tema”. Ocorre que um currículo ou uma prática pedagógica, baseados unicamente nos conteúdos do livro didático, que determinem somente os conteúdos conceituais específicos de determinada área de conhecimento, tornam-se insatisfatório para uma formação crítica do professor de física.

Documentos oficiais, como os Parâmetros Curriculares Nacionais (BRASIL, 2000) e os Parâmetros Curriculares Nacionais + Física (BRASIL, 2002) e a literatura especializada (KAWAMURA, 2013) vêm argumentando a necessidade de se considerarem outros aspectos formativos, como as diversas interpretações da formulação de um conceito, a complexidade histórica da construção do conhecimento, o vínculo desse conhecimento com a dinâmica de todo o currículo, além de questões de caráter ontológico, filosófico e epistemológico que possam ser congruentes com o conteúdo a ser trabalhado.

O professor em formação inicial desenvolve concepções a respeito de fenômenos baseadas em crenças, explicações, princípios intuitivos e significados desenvolvidos a partir de suas interações particulares com o mundo - por isso, espontâneas (ZYLBERSTAJN, 1983), as quais são fortemente incorporadas à estrutura cognitiva, tornando-se altamente resistentes à instrução (MORTIMER, 1996) ${ }^{2}$. Assim, dada a importância dos livros didáticos neste processo de ensino e aprendizagem, a visão fomentada por esses livros nos professores em formação inicial impregna suas visões estéticas dos conceitos, em um processo similar ao dessas concepções espontâneas. Esses conceitos podem nortear a formação da estrutura de pensamento do indivíduo e, dessa forma, serem reproduzidos em sala de aula durante a atuação profissional. Pouco sabemos, entretanto, quais das visões utilizadas pelos livros de ensino superior na licenciatura são alimentadoras ou buscam atingir essas concepções dos estudantes. Para discutirmos este problema, dada a complexidade de diversos conceitos presentes em quaisquer livros, a pergunta de nosso trabalho é: qual é a concepção de estética e de simetria presente em alguns livros didáticos de física utilizados em cursos de formação de professores que permeia as leis de Newton? Ao buscar responder a essa pergunta, queremos contribuir para uma maior reflexão sobre o tema, de modo a pensarmos em implicações para o ensino das leis de Newton a partir dessa perspectiva.

\footnotetext{
2 Os trabalhos de Zylberstajn (1983) e Mortimer (1996) têm seu foco na concepção espontânea de alunos aprendizes de física, os quais são, a nosso ver, próximos dos estudantes de licenciatura.
} 


\section{Metodologias da pesquisa}

Para atingirmos nosso objetivo, primeiramente estudamos como eram compreendidos os conceitos de estética e de simetria na antiguidade. Para tanto, seguimos a orientação de Martins (2004) para a realização de pesquisas bibliográficas com viés histórico-filosófico, utilizando fontes secundárias ${ }^{3}$ de diferentes períodos, visando uma compreensão mais ampla de tais conceitos, estudados a partir de exemplos concretos. Com isso, buscamos criar possibilidades para estudarmos possíveis concepções anteriores, posteriores e contemporâneas a Newton, acerca de estética e simetria na interpretação dos fenômenos físicos, mais especificamente sobre suas leis, evitando os riscos de anacronismos (FORATO; PIETROCOLA; MARTINS, 2011). Em seguida, fizemos uma pesquisa bibliográfica (LUDWIG, 2014; AZANHA, 1992) em dicionários sobre as palavras "estética' e "simetria" e em banco de teses, dissertações, revistas, artigos e trabalhos disponíveis nos anais de eventos envolvendo a pesquisa no ensino de física, que teriam defendido a importância de tais aspectos para uma formação crítica e reflexiva sobre o desenvolvimento das ciências. Para tanto, utilizamos as palavraschaves "estética", "simetria", "estética + simetria", sempre associadas às leis de Newton, à mecânica ou ao ensino de física. Encontramos poucos trabalhos sobre o tema.

Após essa pesquisa sem grandes resultados, concentramo-nos no estudo da obra de dois autores contemporâneos (MENEZES, 2005, 2011; PRIGOGINE, 1996) que dedicaram grande empenho ao estudo do tema. Foi a partir da obra desses autores que estabelecemos critérios para propormos um instrumento de análise para todo o trabalho, de modo a construirmos um estudo acerca das concepções de estética e simetria presentes na apresentação das leis de Newton em cinco livros didáticos de ensino superior costumeiramente utilizados em cursos de licenciatura em física. Como não encontramos uma metodologia consagrada na literatura que fundamentasse nossa pesquisa sobre os livros, adotamos critérios baseados em alguns elementos utilizados nas análises de livros didáticos realizadas por Leite e Hosoume (2005), como a identificação do enfoque conceitual que enfatiza a presença e o formato das discussões; e em alguns elementos utilizados por Martorano e Marcondes (2009), como a identificação da concepção que se atribui aos fenômenos cotidianos e à visão de ciência

\footnotetext{
3 No presente caso, para estudarmos a visão da estética e da simetria na antiguidade, estudamos os seguintes autores: Quadros (1986), Kirchof (2003), Suassuna (2008) e Talon-Hugon (2009). Para os estudos específicos das leis de Newton do ponto de vista historiográfico, destacamos os seguintes autores: Cohen e Westfall (2008); Westfall (1995), Forato (2006) e Martins (2012).

4 A fim de buscar outros trabalhos, publicados nos últimos dez anos, que pudessem corroborar com a nossa análise, consultamos as palavras-chave 'análise livros ensino superior' no banco de teses da Coordenação de Aperfeiçoamento de Pessoal de Nível Superior (CAPES), e os bancos de dados da biblioteca eletrônica SciELO Brasil e da Fundação de Amparo à Pesquisa do Estado de São Paulo (FAPESP), não recebendo o retorno de nenhum resultado. Buscamos, também, os históricos do Encontro Nacional de Pesquisa em Educação em Ciências (ENPEC), da Associação Brasileira de Pesquisa em Educação em Ciências (ABRAPEC), e os bancos de memórias dos Encontros de Pesquisas em Ensino de Física (EPEF) e Simpósios Nacionais de Ensino de Física (SNEF) - os dois últimos promovidos pela Sociedade Brasileira de Física (SBF) -, não sendo encontrados trabalhos com resultados de análises de livros de física para o ensino superior.
} 
transmitida, além de discussões referentes à natureza da ciência, como a argumentação e a visão não linear, não neutra e ahistórica da ciência.

Os livros foram selecionados a partir da consulta de ementas de física básica e do corpo docente do departamento de física da Universidade Federal de São Paulo para o primeiro ano de formação de professores em um curso de licenciatura na área. Selecionamos os cinco livros que apareceram com maior frequência em nossa consulta. O quadro a seguir apresenta a lista de livros selecionados.

Quadro 1 - Livros didáticos analisados.

\begin{tabular}{|c|c|c|c|}
\hline Título do livro & Autores & Editora & Ano / Edição \\
\hline $\begin{array}{l}\text { Física para cientistas e engenheiros - Mecânica, } \\
\text { Oscilações e Ondas, Termodinâmica, Volume } 1\end{array}$ & TIPLER & LTC & $2000 / 4^{\mathrm{a}}$ ed. \\
\hline Fundamentos da Física - Mecânica, Volume 1 & $\begin{array}{l}\text { HALLIDAY, } \\
\text { RESNICK e } \\
\text { WALKER }\end{array}$ & LTC & $2008 / 8^{\mathrm{a}}$ ed. \\
\hline $\begin{array}{l}\text { Princípios de Física, Volume 1: Mecânica Clássi- } \\
\text { ca }\end{array}$ & $\begin{array}{l}\text { SERWAY e JE- } \\
\text { WETT }\end{array}$ & Cengage Learning & $2009 / 1^{a}$ ed. \\
\hline Física 1: Mecânica & GREF & Editora da USP & $2012 / 7^{\mathrm{a}} \mathrm{ed}$ \\
\hline Física Conceitual & HEWITT & Bookman & $2002 / 9^{a}$ ed. \\
\hline
\end{tabular}

Um detalhamento mais minucioso deste processo segue adiante, ao longo do trabalho.

\section{De que estética e simetria estamos falando?}

O estudo das influências estéticas na interpretação do mundo não é um assunto novo. Desde a tradição poética arcaica grega, ao redor do século VIII a.C., com Homero, Hesíodo, Simônides e Píndaro, a estética, associada à beleza, contendo atributos como perfeição, felicidade, paz e harmonia, era concebida ontologicamente, como um princípio originário, explicativo do cosmos, próprio dos deuses - e não no sentido contemporâneo, que agrega aspectos matemáticos (QUADROS, 1986). Na antiguidade, Sócrates foi um dos primeiros pensadores a refletir sobre questões estéticas, relacionando-as à investigação da natureza do belo, em seus diálogos com Hípias. Nesses diálogos, escritos por Platão, Sócrates pressupõe que belo é aquilo que é útil e que pode ser proveitoso, que provoca prazer e é atravessado pelos sentidos. Ele, todavia, se vê incapaz de definir o belo, objetivamente, uma vez que julga que o que é belo é difícil. Ainda que não tenha chegado a uma definição, em si, Sócrates refutou conceitos atribuídos ao belo, geralmente de caráter particular - como as definições de belo como a beleza de uma moça, de belo como sendo o ouro, ou de belo como aquilo que é apropriado (TALON-HUGON, 2009). 
Platão, seu discípulo, atribuiu o belo ao plano ideal (mundo das ideias), dissociado do mundo sensível, que conduziria o homem à perfeição e incorporava conceitos como proporção e harmonia, associado ao bem, à verdade e ao imutável (KIRCHOF, 2003; SUASSUNA, 2008; TALON-HUGON, 2009). O belo era o fulgor da ideia de beleza e, ainda que uma ideia possa configurar algo abstrato, para Platão essa ideia era o real, consequentemente, o verdadeiro, o bom e desejável, o que traria a totalidade e a compreensão (QUADROS, 1986). Assim, nos restaria apenas a cópia fiel e/ou a simulação de algo ideal, nos possibilitando a emissão de um juízo estético. Aristóteles, por sua vez, refutou as ideias platônicas e concebeu o belo a partir da realidade sensível, que é a compreensão e o conhecimento do mundo a partir da experiência com os sentidos (mundo material), seguindo critérios de harmonia, grandeza e proporção associados ao ponto de vista objetivo e realista (SUASSUNA, 2008), envolvendo parâmetros como simetria e ordenação (QUADROS, 1986). O belo aristotélico, assim, deixa de ser algo abstrato para se tornar concreto. A estética como harmonia, proporção, ordem, grandeza, adequação simétrica das partes, é, sem dúvida, uma concepção (idem, ibidem).

Buscando mais elementos para compor uma compreensão desses conceitos, consultamos o significado da palavra 'estética' em alguns dicionários, entre eles o Aurélio ${ }^{5}$, Dicio ${ }^{6}$ e Priberam ${ }^{7}$, todos em suas plataformas online. Os dicionários Aurélio e Priberam definiram a estética como "ciência que trata do belo em geral e do sentimento que ele desperta em nós", enquanto o dicionário Dicio a definiu como "ramo da filosofia que se dedica ao estudo do belo, da beleza sensível e de suas implicações na criação artística". Notamos que, em todas as concepções, a palavra 'estética' está diretamente relacionada ao belo, em ressonância às concepções filosóficas da antiguidade. A fim de buscar outras possíveis concepções, consultamos dois dicionários etimológicos. De acordo com o Grande Dicionário Etimológico Prosódico da Língua Portuguesa, de Silveira Bueno (1965), o termo 'estética' vem do grego aisthétikos, em forma feminina, e designa 'filosofia da arte' e 'filosofia do belo'. Quadros (1986, p. 32) acrescenta que esse termo foi introduzido pela primeira vez, em sua concepção moderna como filosofia da arte, pelo filósofo Alexander Gottlieb Baumgarten (1714-1762), que "substantivou a palavra aesthetica, consagrando o nome da disciplina filosófica entre 1735 e 1750". Já no Dicionário Etimológico da Língua Portuguesa, de José Pedro Machado (1987), a palavra 'estética' deriva do francês esthétique, vinda do grego aisthêtiké, forma do adjetivo aisthêtikós, que significa "que tem a faculdade de sentir ou de compreender; que pode ser compreendido pelos sentidos". Vale ressaltar que os sentidos referidos são os sentidos humanos, de forma que tudo aquilo que sensibiliza nos afeta (QUADROS, 1986).

Notamos, dessa forma, que a etimologia da palavra estética está relacionada à percepção e às sensações. Até aqui, a estética nos parecia como algo que atuava no ser humano

\footnotetext{
${ }^{5}$ Dicionário do Aurélio. Disponível em: <https://dicionariodoaurelio.com/>. Acesso em: 17 mai. 2018.

${ }^{6}$ Dicio Online de Português. Disponível em: <https://www.dicio.com.br/>. Acesso em: 17 mai. 2018.

${ }^{7}$ Dicionário Priberam da Língua Portuguesa. Disponível em: <https://www.priberam.pt/dlpo/>. Acesso em: 17 mai. 2018.
} 
dentro de sua interpretação do mundo, numa perspectiva de que "o homem diante do mundo é um intérprete" (QUADROS, 1986, p. 188). O homem percebe e sente o mundo, e o interpreta buscando sentido. A interpretação é o próprio modo do homem conhecer. Dessa forma, a relação entre o homem e o mundo é uma relação de interpretação, a qual é um exercício de formatividade, depreendendo-se daí a teoria do conhecimento. Portanto, existe um caráter estético, isto é, produtivo, formador, inventor, em todo o movimento do conhecer. E esse estético

\begin{abstract}
está onde quer que exista qualquer fazer humano, de qualquer ordem, dimensão ou nível. Está em todo o pensamento, em toda a ação e em toda a realização humana. Isto é: está onde quer que o homem "faça" um pensamento, "faça" uma ação, "faça" uma realização. Porque os pensamentos, as ações e as realizações humanas só existem se "feitas" pelo homem. [...] quando o ser humano faz qualquer coisa, faz um pensamento, uma ação ou uma realização, obra, ou qualquer outra operação, neste fazer ele põe sempre, de alguma forma, sua sensibilidade, seu gosto, sua singularidade, sua coloração, seu estilo, seu "aisthesis" (QUADROS, 1986, p. 38-39. Aspas no original).
\end{abstract}

Da percepção e sensação à interpretação do mundo, "a estética pretende despertar em nós um novo modo de ver" (QUADROS, 1986, p. 41). Ainda que reconheçamos os riscos de uma visão anacrônica, e admitindo a limitação e a impossibilidade de maior aprofundamento histórico e filosófico acerca do tema neste artigo, para atingir nosso objetivo, buscamos, até este momento, resgatar as concepções primárias da antiguidade e os significados etimológicos, além de estudar referenciais que discutiram o tema no século XVII e na atualidade, a fim de definirmos uma compreensão autoral deste conceito.

Após todo esse processo, passamos a adotar a estética como 'a visão, o gosto, as percepções e outras ações decorrentes dos nossos sentidos, e as interpretações as quais atribuímos às coisas'. Assumimos, portanto, uma noção kantiana da estética que, no processo de construção do conhecimento científico, pode ocorrer a partir da contemplação que um indivíduo faz de um determinado fenômeno e que, ao mesmo tempo, é utilizada pelo mesmo para intuir e refletir sobre o que está a contemplar, de modo que nenhuma teoria natural é formulada de forma isolada do ser humano, dependendo sempre de quem está a contemplar a natureza, bem como das hipóteses e questões estéticas internas que este indivíduo traz consigo (KANT, [1790] 1993).

A estética é, assim, inerente ao ser humano - ainda que possa sofrer interferência de uma cultura ou de um coletivo no qual o sujeito está inserido - e atua diretamente em sua forma de sentir, interpretar e construir o mundo, admitindo-se a simetria, por sua vez, um de seus elementos primordiais. Posto isso, não a compreenderemos no seu sentido moderno como a 'filosofia da arte', introduzido por Baumgarten e amplamente difundido a partir do filósofo alemão Georg W. F. Hegel (1770-1831), que relaciona a estética ao belo artístico (espiritual, sem a realidade física) (HEGEL, [1820-1829] 1996), sendo contemplada nos diferentes tipos de artes, tais como a música, pintura, poesia e escultura, e distanciada das ciências. 


\section{Estética e simetria na interpretação de alguns conceitos físicos}

Na física, há registros da busca por um certo padrão estético em diferentes momentos de sua construção histórica, em particular a questão da simetria, conforme assinala Menezes (2011):

as simetrias são essenciais nas teorias da física, desde as compreensões clássicas de espaço e tempo, cuja homogeneidade e uniformidade respondem pelas discussões das quantidades de movimentos e energia. [...] Mais do que uma estética científica, se pode pensar sobre as simetrias como uma estética natural reconhecida pela ciência. Além disso, na física e, especialmente, nos fenômenos da vida, não apenas as simetrias, mas também as assimetrias que se mostram determinantes para a compreensão da natureza (p. 90 e 91, tradução nossa).

A estética apresenta caráter subjetivo, posto que é inerente ao ser humano, de modo que a afirmação de que os físicos buscam a beleza exige aprofundamento. Nesse sentido, pode-se mais facilmente compreender seu significado a partir da própria compreensão do que seria, por exemplo, o espaço de acordo com Menezes (2005): pensando em dois pontos quaisquer desse espaço, ambos absolutamente distantes de qualquer campo atrativo ou repulsivo, não haveria quaisquer razões para que as propriedades presentes em um deles fossem diferentes das propriedades de outro nas mesmas condições. Ou seja, os dois seriam absolutamente simétricos entre si. As diferenças entre eles ocorrem quando, por exemplo, é acrescentado um sistema de referência - escolha humana e externa a ele, no qual poderíamos expressar numericamente diferentes posições de um e de outro em função dessa referência. Por outro lado, se um deles estiver numa região em que há um campo gravitacional, então uma massa presente neste ponto teria efeitos diferentes de outra colocada num outro ponto em que não há esse campo. Diríamos, então, conforme esse autor, que tanto a adoção do sistema de referência quanto a existência de um campo são agentes que quebram a simetria entre os pontos. Notese, aqui, que a implantação do sistema de referência (seu formato, o lugar em que será localizado, etc.), por sua natureza essencialmente de escolha humana, tem forte influência da questão estética: não à toa, o sistema de referência mais comum é o plano espacial, cujo formato assemelha-se em demasia a lados de um cubo, como veremos na sequência.

Ainda segundo o mesmo autor, sendo todos os pontos equivalentes, podemos dizer que o espaço é homogêneo (MENEZES, 2005), isto é, possui exatamente as mesmas propriedades em quaisquer pontos. A homogeneidade revela uma simetria do espaço. A existência de um campo gravitacional, por sua vez, estabelece a perda local da homogeneidade, ou seja, causa uma assimetria. Essa assimetria do espaço devido à gravitação é a responsável por condicionar o desenvolvimento e o movimento na crosta terrestre. Por razões práticas, as coisas aqui na Terra são construídas seguindo planos horizontais, que são homogêneos; enquanto os planos verticais têm sua equivalência de pontos quebrada pela gravidade. 
A homogeneidade do espaço implica, também, na impossibilidade de existir movimento em apenas um sentido, sem a compensação desse movimento no sentido oposto. $\mathrm{Ou}$ seja, a homogeneidade do espaço implica na conservação da quantidade de movimento translacional ou momento linear (MENEZES, 2005).

O espaço, no entanto, possui outra notável simetria refletida nas rotações denominada isotropia. O espaço vazio é isotrópico, ou seja, não possui direção privilegiada. Assim como a homogeneidade está ligada à conservação de quantidade de movimento linear, a isotropia se relaciona à conservação de quantidade de movimento rotacional ou momento angular. Dessa forma, a existência do campo gravitacional terrestre quebra tanto a homogeneidade quanto a isotropia do espaço na componente vertical. A existência do campo magnético também quebra a isotropia (MENEZES, 2005). O ponteiro de uma bússola, por exemplo, sempre buscará apontar na direção norte. Se o campo magnético não existisse, não haveria razão para que a bússola apontasse sempre para o norte. A isotropia é a propriedade responsável pela garantia de que, salvo a existência de um torque, um objeto que não esteja em rotação não começará a girar de forma espontânea. A existência de um torque, por sua vez, expressa uma anisotropia local, ou seja, uma quebra local de simetria angular, rotacional. Corpos em rotação podem manter sua rotação sem quaisquer alterações graças à isotropia. Análoga à homogeneidade, a isotropia implica na impossibilidade de se gerar movimento rotacional em apenas um sentido, sem a existência de um movimento de compensação, girando, de forma proporcional, no sentido oposto.

Além de simetrias e quebras de simetrias associadas ao espaço, podemos também analisar o tempo que possui duas características relacionadas à simetria: a uniformidade com que flui (na física clássica, não há alteração entre as passagens de cada segundo, por exemplo); e à assimetria: a irreversibilidade do mesmo. Uma propriedade bastante óbvia que pode ser ilustrada é o fato reconhecido de que o tempo não volta atrás. Em termos estéticos, é essa assimetria relativa à orientação do passado para ao futuro que impossibilita a inversão do sentido do tempo. Se não fosse assim, aceitaríamos, sem espanto, cenas regredindo, como um filme sendo visto ao contrário. Aceitaríamos, por exemplo, uma "desmordida na maçã" (MENEZES, 2005, p. 53).

As simetrias e assimetrias temporais são, ao lado da conservação das quantidades de movimentos linear e rotacional, algumas das ideias centrais da física. Vê-se aqui os denominados princípios de conservação do movimento. Segundo Menezes (2005) e Prigogine (1996), a convicção na existência de propriedades estéticas do espaço pautadas em simetrias estabelece uma forma de compreender e quantificar os diferentes movimentos e fenômenos mecânicos cotidianos. Assim sendo, para nós, uma investigação baseada nessas convicções parece decisiva na compreensão dos conceitos físicos, além de contribuir com a estruturação do pensamento científico do professor em formação. 


\section{A importância da estética e da simetria nas leis de Newton}

Inferimos que os conceitos de estética e simetria, compreendidos nos moldes apresentados por Menezes $(2005 ; 2011)$ e Prigogine (1996) e próximos às nossas escolhas, podem nortear a compreensão das bases que fundamentam as leis de Newton, as quais afirmam que tanto os movimentos do nosso cotidiano quanto o movimento de todo o Cosmos são regidos a partir dos princípios de conservação da quantidade de movimento linear e rotacional, implicando na manutenção ou quebra da simetria dos movimentos, partindo-se do pressuposto de que nenhum movimento pode acontecer isoladamente, ou seja, todo movimento deve ser resultado, originalmente, de uma interação entre duas ou mais partes de um sistema ou entre dois ou mais sistemas. Por essa razão, fizemos uma pesquisa bibliográfica com fontes secundárias com o tema "leis de Newton", visando obter indícios da compreensão dessa concepção de estética e simetria que, conforme acreditávamos, possivelmente estiveram em suas formulações originais. Pretendíamos, com isso, obter mais fundamentos para subsidiar nossa análise dos livros.

Muitos cientistas, filósofos e historiadores concordam e apontam as obras de Isaac Newton (1642/1643-1727) ${ }^{8}$ como o auge da Revolução Científica do século XVII (COHEN e WESTFALL, 2002). Dentre elas, a principal obra de Newton foi a publicação Philosophiae Naturalis Principia Mathematica (Princípios Matemáticos da Filosofia Natural), considerada uma das mais influentes na história da ciência, escrita inteiramente em latim, língua das ciências da época, e publicada em 1687 com o incentivo de Edmund Halley (1656-1742), em três volumes. Westfall (1995, p. 162) destaca que "os Principia não foram apenas a realização monumental de Newton. Foram também a guinada decisiva em sua vida", que, dada a sua magnitude, lançou sobre Newton grande notoriedade. Nesta obra, Newton contribuiu em diferentes frentes. Dentre suas propostas, podemos destacar três avanços significativos para a época: uma lei única para escrever o movimento dos corpos na terra e nos céus, a matematização que fundamenta essa lei e uma proposta metodológica para investigar os fenômenos da natureza. Havia, porém, uma concepção de espaço por trás delas, de acordo com referenciais que se debruçaram sobre a filosofia newtoniana. Segundo Thackray (1968), para Newton, o Universo era uma entidade quase inteiramente vazia. Já para Koyré (1965), o espaço newtoniano era constituído de um vazio infinito e homogêneo e, para McGuire e Rattansi (1966), o trabalho de Newton sofreu fortes influências dos platônicos de Cambridge, que acreditavam em um espaço vazio e absoluto. Dessa forma, podemos inferir já alguns elementos de estética que fundamentavam o espaço newtoniano, segundo esses referenciais: vazio e com algumas propriedades, como a infinitude e a homogeneidade.

\footnotetext{
${ }^{8}$ Enquanto Newton esteve vivo, dois calendários eram utilizados na Europa: o juliano na Grã-Bretanha e partes do norte e leste da Europa, e o gregoriano, utilizado pela Europa Católica Romana (instituído em 1582, mas adotado na Inglaterra somente após 1752). No nascimento de Newton, as datas no calendário gregoriano eram dez dias adiantados do juliano; assim, Newton nasceu em 25 de dezembro de 1642 no calendário juliano, mas no dia 4 de janeiro de 1643 no gregoriano. Já na época de sua morte, a diferença de dias entre seus calendários passou para onze dias, variando sua morte entre 20 e 31 de março de 1727.
} 
Acrescente-se a isso, outra importante propriedade, citado pelo próprio Newton em um manuscrito à Royal Society, datado em 1702:

\begin{abstract}
[...] Lucrécio ensina que não existe um centro no Universo, nem tampouco um lugar mais baixo, mas que há mundos espaciais infinitos [...] se todo o espaço do Universo estivesse contido em fronteiras fixas por todos os lados e fosse limitado, então, a essa altura, o reservatório de matéria, por seu peso sólido, teria se juntado de todos os lados e corrido para o fundo (MCGUIRE; RATTANSI, 1966, p. 114. Grifos nossos. Tradução nossa).
\end{abstract}

Num outro manuscrito da Royal Society, também de 1702, Newton escreveu:

\begin{abstract}
A força da argumentação é que, se a natureza das coisas fosse limitada a qualquer direção, os corpos mais distantes, já que não teriam nenhum corpo além deles para o qual gravitar, não se manteriam em equilíbrio, mas, por sua própria gravidade, se deslocariam para as coisas internas e, fluindo juntos de todas as regiões, desde tempo infinitos, há muito se haveriam depositado no centro do todo, como se fosse o lugar mais baixo (MCGUIRE e RATTANSI, 1966, p. 114. Grifos nossos. Tradução nossa).
\end{abstract}

O espaço newtoniano não apresentava um centro definido para o Universo, tampouco limitava direções específicas para o movimento dos corpos. Dessa forma, inferimos que o espaço newtoniano era, também, isotrópico, conforme a concepção de Menezes. E é através dele que aconteciam as interações e movimentos de toda a matéria, ainda que a introdução do vazio - contrariando a filosofia do plenum cartesiano ${ }^{9}$ - resultasse em diversas complicações físicas, e até metafísicas, como a existência do nada e a ação a distância. Segundo Forato, Pietrocola e Martins (2007, p. 6), "dentro do ideário alquímico havia a ideia de um espaço transmitindo uma ação entre os corpos, ou seja, a ideia de forças agindo à distância. Tal concepção permitiu que ele [Newton] elaborasse sua Gravitação Universal”. Segundo Dobbs (1984 apud FORATO, PIETROCOLA e MARTINS, 2007), Newton cria que a existência de forças que atuam à distância, numa interação não mecânica entre as partículas, requer a presença de Deus na ordem natural, que aparece para ele como causa da gravidade. Essa concepção [do vazio] permitiu a Newton dar um passo além de seus contemporâneos, unindo, de forma simultânea, "a continuidade do espaço e a descontinuidade da matéria" (KOYRÉ, 1968, reproduzido em COHEN e WESTFALL, 2002, p. 91). Esse passo, talvez, tenha sido um dos mais importantes dentro da filosofia newtoniana. Além dessas características, os historiadores McGuire e Rattansi (1966) destacam que Newton atribuía à sua concepção de espa-

\footnotetext{
${ }^{9}$ Segundo Cohen e Westfall (2002, p. 20), àquela época Descartes equacionava a matéria com a extensão e insistia em que o espaço não poderia ser vazio, como seria se existisse um vácuo perfeito; o espaço era repleto de algum tipo de matéria; em outras palavras, o Universo era um plenum [...] [Descartes] descrevia o céu como um conjunto de imensos redemoinhos ou vórtices, em que o nosso Sol estaria no centro de um desses vórtices e os planetas seriam arrastados em torno dele como gravetos flutuando na água [...] Descartes afirmava que nenhuma partícula era indivisível.
} 
ço a ideia de "harmonia' ${ }^{10}$, que representaria a real causa da movimentação dos corpos massivos por todo o Universo (FORATO, 2008; McGUIRE; RATTANSI, 1966).

Cohen e Westfall (2002) destacam um conjunto de definições dos conceitos fundamentais, que serviram de base para a ciência da mecânica. Essas definições, que dificilmente aparecem em livros-textos (didáticos) e de divulgação científica de física, foram escritas pelo próprio Isaac Newton e estão presentes no começo do texto dos Principia. Os autores destacam, também, um escólio - que se trata de anotações sobre textos, com a finalidade de explicá-lo ou torná-lo mais claro - formado por declarações de convicção pessoal de Newton. Essas definições são, além de interessantes, essenciais, no sentido de mostrarem as bases sobre as quais se apoia a filosofia newtoniana, especificamente seus axiomas de movimento e toda sua dinâmica. Eis dois deles (grifos nossos):

1. O tempo absoluto, real e matemático, por si só e por sua natureza flui uniformemente, sem relação com qualquer coisa externa, e recebe também o nome de duração; o tempo relativo, aparente e comum é uma medida sensível e externa (precisa ou desigual) da duração por meio do movimento, que é comumente usado no lugar do tempo verdadeiro, como uma hora, um dia, um mês ou um ano.

Apesar das simetrias temporais ficarem mais claramente explicitadas a partir das leis da mecânica, em que as equações atribuídas à mecânica newtoniana são reversíveis no tempo (considerando-se sistemas conservativos), e da assimetria do tempo estar diretamente relacionada à segunda lei da termodinâmica, é importante enfatizar que Isaac Newton viveu em uma época anterior à proposição atual dessas ideias, tais quais as conhecemos hoje. Porém, ao dizer, em seus escólios que o tempo "flui uniformemente", inferimos que Newton estabelece uma simetria de transcurso no tempo. Podemos supor, também, que o tempo newtoniano possui uma assimetria: ele passa em um só sentido, sendo, portanto, irreversível. Se o tempo newtoniano não tivesse essa assimetria, seria aceitável, em sua filosofia, que as ações cotidianas pudessem recuar no tempo.

2. O espaço absoluto, em sua própria natureza, sem relação com qualquer coisa externa, mantém-se sempre semelhante e imóvel. O espaço relativo é certa medida ou dimensão móvel dos espaços absolutos, que os nossos sentidos determinam por sua posição em relação aos corpos, e que é comumente tomado pelo espaço imóvel; assim é a dimensão de um espaço subterrâneo, aéreo ou celeste, determinada por sua posição com respeito à Terra. $\mathbf{O}$ espaço absoluto e o relativo são iguais na forma e na magnitude, mas nem sempre sem mantêm numericamente os mesmos 11 .

\footnotetext{
${ }^{10}$ Para Newton, um Universo ordeiro e toda a dependência da matéria, em sua existência e movimento, dependeria da vontade de Deus, expresso pelos antigos através da ideia de harmonia. Newton via na analogia com a harmonia musical os princípios da lei e da ordem no mundo natural. Para ele, essa harmonia era a expressão mais profunda do Cosmos. Para maior profundidade do tema, sugerimos a leitura de McGuire e Rattansi, 1966 e de Forato, 2006.

11 Vale salientar que a teoria clássica de campos não havia sido proposta nessa época, portanto, nem o espaço newtoniano, tampouco sua filosofia, contam com proposições dessas teorias.
} 
Portanto, inferimos que as propriedades absolutas do espaço newtoniano, descritas até aqui como homogeneidade e harmonia, implicam que um movimento inerte não possui razão para alterar esse estado, o que configura a primeira lei de Newton, tida como axioma e que "tem a função de uma definição daquilo que é considerado o "movimento de referência" da mecânica newtoniana" (MARTINS, 2012, p. 6, aspas no original). A segunda lei, também conhecida como princípio da dinâmica, apresenta a atividade de corpos em movimentos não inerciais. Essa lei implica diretamente na formulação do conceito de força. Para chegar a esse conceito, no entanto, Newton precisou dar alguns passos ${ }^{12}$. Novamente, vemos a questão estética relacionada à contemplação de Newton acerca do funcionamento do mundo, baseada em suas visões, percepções e interpretações pessoais, as quais intuía e atribuía questões internas em sua concepção, como a oposição ao plenum cartesiano e o papel de Deus na ação de forças a distância; e relacionadas aos sentidos, como determinante da segunda lei nas forças de contato, pois, conforme aponta Jammer (1979, p. 137, reproduzido em NEVES, 2000, p. 52), "força era um conceito dado a priori, intuitivamente, e, em última análise, em analogia à força muscular do homem".

A partir da compreensão das obras de Galileu e Descartes, parece-nos como central na ciência contemporânea a utilização, por Newton do plano cartesiano, associado a um referencial inercial. A partir disso, ele relacionou o espaço e o tempo, em que a variação do primeiro em relação ao segundo resultaria no conceito de velocidade ${ }^{13}$. A adoção do sistema de referência, ou plano espacial que se assemelhasse com o vértice de um cubo, figura proveniente de um quadrado, pareceu-nos uma questão estética bastante evidente, posto que a compreensão de um mundo em que as coisas parecem ser quadradas, ou de algum formato geométrico derivado, nos orienta a construir os conceitos e as imagens com essa forma ${ }^{14}$. A própria

12 Para chegar a essa ideia, Westfall (1995) destaca que, Newton leu obras sobre a filosofia mecânica, fonética, propostas para uma língua universal, estudou sobre a cronologia e profecias bíblicas, além do currículo oficial da escola, baseado na tradição aristotélica. Leu o 'Diálogo sobre os dois principais sistemas do mundo', de Galileu, partes da obra de Euclides e mergulhou na 'Geometria' de Descartes até dominar sozinho seu conteúdo. Estudou as leis do movimento planetário de Kepler, leu ainda obras que tratavam da análise moderna da matemática e, em cerca de um ano, ele não só dominava a matemática do século XVII, como também estava apto a iniciar a trajetória onde traria contribuições. No início da década de 1670, Newton começou as primeiras reflexões sobre o que viria a ser o princípio da inércia como o conhecemos. Estudou e pesquisou colisões e as forças envolvidas no movimento circular. Tais proposições, conceitualmente diferentes do que lera em Descartes e Galileu, remeteram ao problema do quê mantém a Lua em órbita. A partir dessas análises e utilizando a terceira Lei de Kepler, Newton constatou que o "esforço que um planeta faz em sua órbita para se afastar do Sol" é proporcional ao inverso do quadrado da distância entre o planeta e o Sol. Alguns anos depois, iniciaria um estudo teórico e experimental sistemático sobre alquimia, que ainda contribuiria para a formulação de sua Gravitação Universal. Veja uma brevíssima biografia de Newton, disponível em:

<http://www.ghtc.usp.br/Biografias/Newton/Newton3.htm>. Acesso em 11 de junho de 2018.

13 Vale ressaltar que, posterior a Newton, foi apresentada a ideia da variação da velocidade em função do tempo, chegando ao conceito de aceleração - este, no entanto, não se trata de um conceito newtoniano, posto que Newton baseou suas leis a partir da modificação da quantidade de movimento (WESTFALL, 1995).

14 Quando olhamos o horizonte, o vemos como uma linha reta. Quando olhamos para a superfície de um lago, este nos parece plano. Os troncos das árvores, normalmente, nos parecem ortogonais ao solo terrestre. Nos parece que uma boa razão para isso é que o quadrado equilibra a gravidade. Ademais, segundo Menezes (2005), o quadrado é uma das figuras geométricas mais simples, simétrica e esteticamente perfeita que temos na natureza. 
geometria euclidiana, fundamental no plano cartesiano e baseada em três dimensões, orienta a existência de um mundo em que o formato quadrado parece guiar a compreensão humana e, portanto, torna-se o formato mais natural dentro das construções geométricas possíveis.

Parece-nos plausível conjecturar que há elementos de estética perceptíveis tanto na escolha do sistema de referência baseado nos lados de um cubo, quanto na ideia de um movimento referência (inercial, perfeito).

Outros elementos estéticos podem ter influenciado Newton ao considerar a massa como uma quantidade física inerente à natureza dos corpos materiais que se mantinha inalterada ao longo de todas as mudanças de movimento. A percepção da importância da massa parece-nos, por si mesma, uma consequência direta e objetiva do sentido visual e tátil do ser humano - portanto, altamente derivado de uma concepção estética. Pelas palavras de Newton, "a quantidade de matéria é o que decorre conjuntamente de sua densidade e sua magnitude. Um corpo duas vezes mais denso no dobro do espaço tem o quádruplo na quantidade. Essa quantidade, eu a designo pelo nome de corpo ou massa" (reproduzido em WESTFALL, 1995, p. 166). Westfall (1995, p. 167) ressalta que "na formulação clássica do século XVII, a matéria era irrelevante para o movimento". Newton tornou-a relevante.

A massa estabeleceria, além da quantidade de matéria, a dificuldade de se alterar o estado de movimento. Somente a partir da definição da massa, com evidente subjetividade destacada pelo próprio Newton, ele pôde estabelecer o que seria a quantidade de movimento, fundamental na elaboração de suas leis. (WESTFALL, 1995).

Curiosamente, a forma mais difundida de expressar a segunda lei de Newton é a $\vec{F}=m \vec{a}$. Entretanto, lendo as definições e as leis (axiomas) juntos, podemos depreender que esta equação não está explícita nessa forma ${ }^{15}$. Westfall (1984 apud NEVES, 2000), argumenta que

a segunda lei e as definições ligadas a ela introduziram realmente o conceito na mecânica racional. [...] Usando os termos a rigor, as palavras de Newton [no enunciado de sua segunda lei] dizem que $F=\Delta m v$, e não $F=m a$, nem $F=d(m v) / d t$, formas da segunda lei que nos são familiares.

Como ressalta Truesdell (1968, p. 167),

enquanto os físicos chamam estas de "equações de Newton", elas não aparecem em nenhum lugar do trabalho de Newton ou de qualquer outro antes de 1747. É verdade que hoje podemos lê-la facilmente nas palavras de Newton, mas o fazemos por elaboração a posteriori (reproduzido em NEVES, 2000, p. 553).

\footnotetext{
15 De fato, a definição $\vec{F}=m \vec{a}$ foi escrita, pela primeira vez, somente em 1747, por Leonhard Paul Euler (1707 - 1783) (NEVES, 2000), que inferiu a equação da forma: $F_{k}=m_{k} \ddot{x}_{k}$, em que $F_{k}$ é a força que age sobre o késimo corpo; $m_{k}$ é a massa desse corpo; e $\ddot{x}_{k}$ é a derivada segunda da posição desse corpo.
} 
A terceira lei, por fim, estabelece a impossibilidade de se gerar movimento em apenas um único corpo. Dessa forma, a atuação das forças sempre acontece em pares.

Sintetizando, das nossas inferências após intensa pesquisa, o espaço newtoniano, puro, sem a interação de quebras de simetria como a gravitação, ou a atuação de forças externas ao sistema, é homogêneo, o que implica na conservação do estado de movimento de qualquer corpo. "Isso significa a permanência em repouso do que estiver em repouso, ou a manutenção da direção e do valor da velocidade do que estiver se movendo" (MENEZES, 2005, p.41). Eis aqui a enunciação da primeira lei de Newton. A aplicação de uma força externa pode causar a modificação do estado de movimento de um corpo material. A quantidade de movimento alterada possui um valor relativo, que depende do observador. Isso significaria "uma alteração local da simetria do espaço em que se realiza o movimento" (idem, ibidem, p.53). Eis aqui a segunda lei de Newton. A terceira lei estabelece a impossibilidade de se gerar movimento em apenas um único corpo, de modo a manter a homogeneidade do espaço. Sendo assim, "é o movimento da matéria que revela a simetria do espaço" (idem, ibidem, p.52).

\section{Estética e simetria sobre as leis de Newton nos livros do ensino superior}

Defendemos, na introdução deste trabalho, que o livro didático não atua como auxiliar do processo de transmissão do conhecimento, mas como modelo padrão, autoridade absoluta, critério último de verdade: parece modelar os professores (LOPES, 1992). Além disso, consideramos que o processo de transposição didática não é neutro (CHEVALLARD, 1991), ou seja, ele não depende apenas das ciências de referência, pois traz consigo influências de outros fatores, como as intervenções de elites intelectuais e do poder político institucional. Ainda assim, o livro pode ser o único texto que o aluno tem acesso na hora de estudar certos conceitos científicos (MARTORANO; MARCONDES, 2009). Dessa forma, uma análise dos livros utilizados na formação inicial de professores de física poderia nos guiar para a reflexão sobre quais fatores são considerados na apresentação dos conceitos e como esses conceitos podem ser interpretados e naturalizados (e, posteriormente, ensinados) pelo professor em formação.

Além disso, ainda que existam as especificidades decorrentes dos contextos formativos, Kawamura (2013, p. 50) afirma que "as estruturas curriculares, pelo menos do ponto de vista das disciplinas básicas de conhecimento específico em física, em quase todos esses cursos, são sempre as mesmas, com ementas e bibliografias equivalentes". Ou seja, ainda que mudem as instituições e projetos pedagógicos, as formações iniciais dos professores são pautadas por sequências de conteúdo, livros e materiais didáticos, que pouco diferem entre si, e pouco diferem do início da formação de um pesquisador em física. Há, por trás disso, segundo a autora, a crença de que o conhecimento em física é único, havendo apenas uma forma de organizar e estruturar seu ensino e aprendizagem, o que é corroborado por ser a física uma ciência considerada paradigmática, com leis universais e bem estabelecidas. Segundo Kawamura (2013, p. 53 e 54): 
os docentes universitários têm, em geral, dificuldades em perceber as preponderâncias da sequência curricular, não só pelas suas práticas, nem só pelas concepções intrínsecas do modelo de racionalidade técnica, mas, sobretudo, pelas vivências que tiveram. Sua formação os faz acreditar que a seleção de conteúdos e abordagens na formação superior que tiveram é a única possível, é intrínseca e essencial à física. Confundem o conhecimento da física com o currículo de física que vivenciaram, vivenciam e provavelmente continuarão vivenciando (Grifos nossos).

Ademais, há pesquisas que mostram o quanto houve de mudanças nas proposições iniciais da ciência e suas transposições para os livros didáticos, os quais, realmente apresentam outros objetivos (BRAGA; GUERRA; REIS, 2008). Consideramos isso legítimo e acreditamos que não necessariamente há consequências negativas decorrentes desta transposição. Ao buscarmos lançar luz em como os livros didáticos fazem a transposição da estética e da simetria nas leis de Newton, queremos encontrar elementos que esclareçam esses aspectos, em vez de meramente julgá-los, portanto.

O quadro 2, logo abaixo, apresenta as informações referentes aos objetivos de cada edição analisada, presentes nos prefácios dos livros, assim como o seu público alvo, de acordo com seus autores. Os grifos são todos nossos.

Quadro 2 - Objetivos e público alvo.

\begin{tabular}{|c|c|c|c|c|c|}
\hline & $\begin{array}{c}\text { TIPLER } \\
(2000)\end{array}$ & $\begin{array}{c}\text { HALLIDAY, } \\
\text { RESNICK e } \\
\text { WALKER } \\
(\mathbf{2 0 0 8 )}\end{array}$ & $\begin{array}{c}\text { SERWAY e } \\
\text { JEWETT } \\
(2009)\end{array}$ & GREF (2012) & $\begin{array}{c}\text { HEWITT } \\
(2002)\end{array}$ \\
\hline $\begin{array}{l}\text { Objetivos } \\
\text { da edição }\end{array}$ & $\begin{array}{l}\text { Ajudar os estu- } \\
\text { dantes a aumen- } \\
\text { tar a experiência } \\
\text { e a capacidade } \\
\text { de resolução de } \\
\text { problemas; } \\
\text { facilitar a leitura } \\
\text { do texto, tor- } \\
\text { nando-o mais } \\
\text { agradável; mo- } \\
\text { dernizar a apre- } \\
\text { sentação da } \\
\text { física [...] flexi- } \\
\text { bilizar o texto, } \\
\text { permitindo que } \\
\text { o professor } \\
\text { adote grande } \\
\text { variedade de } \\
\text { formatos no } \\
\text { curso (p. vii). }\end{array}$ & $\begin{array}{l}\text { Proporcionar aos } \\
\text { professores um } \\
\text { instrumento } \\
\text { através do qual } \\
\text { possam ensinar } \\
\text { os alunos a estu- } \\
\text { dar assuntos } \\
\text { científicos, iden- } \\
\text { tificar conceitos } \\
\text { fundamentais, } \\
\text { pensar a respeito } \\
\text { de questões } \\
\text { científicas e } \\
\text { resolver pro- } \\
\text { blemas quanti- } \\
\text { tativos (p. xi). }\end{array}$ & $\begin{array}{l}\text { Fornecer ao } \\
\text { estudante uma } \\
\text { apresentação } \\
\text { clara e lógica dos } \\
\text { conceitos e prin- } \\
\text { cípios básicos da } \\
\text { física, e fortale- } \\
\text { cer a compreen- } \\
\text { são dos concei- } \\
\text { tos e princípios } \\
\text { por meio de uma } \\
\text { ampla gama de } \\
\text { aplicações inte- } \\
\text { ressantes para o } \\
\text { mundo real. [...] } \\
\text { enfatizamos a } \\
\text { metodologia de } \\
\text { resolução de } \\
\text { problemas (p. } \\
\text { xii). }\end{array}$ & $\begin{array}{l}\text { Apresentar a física de } \\
\text { uma maneira que es- } \\
\text { clareça sua relevância } \\
\text { prática e sua universa- } \\
\text { lidade. [...] tornar } \\
\text { significativo esse } \\
\text { aprendizado científico } \\
\text { mesmo para alunos } \\
\text { cujo futuro profissio- } \\
\text { nal não dependa dire- } \\
\text { tamente da física; [...] } \\
\text { dar a todos os alunos } \\
\text { condições de acesso a } \\
\text { uma compreensão } \\
\text { conceitual e formal } \\
\text { consistente, essencial } \\
\text { para sua cultura e para } \\
\text { uma possível carreira } \\
\text { universitária (p. 15). }\end{array}$ & $\begin{array}{l}\text { Construir um } \\
\text { sólido conhe- } \\
\text { cimento con- } \\
\text { ceitual dos } \\
\text { princípios da } \\
\text { física, apre- } \\
\text { sentando-a de } \\
\text { forma interes- } \\
\text { sante, com- } \\
\text { preensível e } \\
\text { relevante, } \\
\text { mesmo para } \\
\text { quem não é da } \\
\text { área. }\end{array}$ \\
\hline
\end{tabular}




\begin{tabular}{|l|l|l|l|l|l|}
\hline $\begin{array}{l}\text { Público } \\
\text { Alvo }\end{array}$ & $\begin{array}{l}\text { Para cientistas e } \\
\text { engenheiros. }\end{array}$ & $\begin{array}{l}\text { Professores e } \\
\text { alunos de assun- } \\
\text { tos científicos. }\end{array}$ & $\begin{array}{l}\text { Estudantes de } \\
\text { engenharia, de } \\
\text { ciências e de } \\
\text { medicina, que } \\
\text { fazem um curso } \\
\text { rigoroso de física } \\
\text { (p. xi). }\end{array}$ & $\begin{array}{l}\text { Professores de física } \\
\text { (p. 15). }\end{array}$ & $\begin{array}{l}\text { Estudantes de } \\
\text { física, em } \\
\text { geral. }\end{array}$ \\
& & & & \\
\hline
\end{tabular}

Vemos, a partir do quadro 2, que a maioria dos livros analisados - Tipler (2000), Halliday, Resnick e Walker (2008), e Serway e Jewett (2009) - apresenta, entre seus objetivos, grande ênfase na metodologia de resolução de problemas, predominantemente, exercícios quantitativos. Essa preocupação em demasia pode proporcionar ao professor em formação uma visão deformada acerca da física, como se a aplicação para resolução de exercícios quantitativos fosse a sua principal tarefa enquanto educador. Essa constatação, a nosso ver, vai ao encontro de uma formação em que o indivíduo não incorpora a relevância da construção humana perante os conceitos físicos e não considera relevante o uso desses conceitos para uma melhor compreensão de situações cotidianas para além das tarefas escolares. Ainda no quadro 2, notamos que embora a maior parte dos livros faça citação direta ao uso pelos professores, seja como instrumento formativo, seja como opção para formatos de cursos, apenas um dos livros, o GREF (2012), é direcionado, explicitamente, à formação de professores de física.

O quadro 3, a seguir, apresenta informações acerca da estrutura dos livros em relação aos conteúdos analisados, como as leis de Newton são apresentadas e quais os enfoques e contextualização do conteúdo em cada um deles.

Quadro 3. Estrutura, apresentação, enfoque e contextualização dos livros.

\begin{tabular}{|c|c|c|c|c|c|}
\hline & TIPLER (2000) & $\begin{array}{c}\text { HALLIDAY, } \\
\text { RESNICK e } \\
\text { WALKER } \\
(\mathbf{2 0 0 8 )}\end{array}$ & $\begin{array}{c}\text { SERWAY e } \\
\text { JEWETT } \\
(2009)\end{array}$ & GREF (2012) & $\begin{array}{c}\text { HEWITT } \\
(2002)\end{array}$ \\
\hline $\begin{array}{l}\text { Estrutura dos } \\
\text { conteúdos }\end{array}$ & $\begin{array}{l}\text { Leis de Newton: } \\
\text { capítulo 4, p. } 76 \\
\text { - 104; } \\
\text { Aplicação das } \\
\text { Leis de Newton: } \\
\text { cap. 5, p. } 105 \text { - } \\
\text { 137; } \\
\text { Sistemas de } \\
\text { Partículas e } \\
\text { Conservação do } \\
\text { Momento: cap. } \\
\text { 8, p. 197 - 237; } \\
\text { Conservação do } \\
\text { Momento Angu- } \\
\text { lar: cap. 10, p. }\end{array}$ & $\begin{array}{l}\text { Força e Movi- } \\
\text { mento - I. Cap. } \\
\text { 5, p. } 95 \text { - 125; } \\
\text { Força e Movi- } \\
\text { mento - II. Cap. } \\
\text { 6, p. } 126 \text { - 151; } \\
\text { Centro de Massa } \\
\text { e Momento Line- } \\
\text { ar. Cap. 9, p. } 217 \\
\text { - 258; } \\
\text { Rolamento, Tor- } \\
\text { que e Momento } \\
\text { angular. Cap. } 11 \text {, } \\
\text { p. } 295 \text { - 326; } \\
\text { Os textos assu- }\end{array}$ & $\begin{array}{l}\text { As Leis do Mo- } \\
\text { vimento. Cap. 4, } \\
\text { p. } 108 \text { - 140; } \\
\text { Aplicações } \\
\text { Adicionais das } \\
\text { Leis de Newton. } \\
\text { Cap. 5, p. } 141 \text { - } \\
\text { 178; } \\
\text { Momento e } \\
\text { Colisões. Cap. } \\
\text { 8, p. } 245 \text { - 280; } \\
\text { Movimento } \\
\text { Rotacional. Cap. } \\
\text { 10, p. } 314 \text { - } \\
\text { 364; }\end{array}$ & $\begin{array}{l}\text { Movimento: } \\
\text { conservação e } \\
\text { variação. Cap. } \\
\text { 1, p. } 27 \text { - 144; } \\
\text { Condições de } \\
\text { equilíbrio. } \\
\text { Cap. 2, p. } 145 \\
\text { - 170; } \\
\text { Os textos } \\
\text { buscam discu- } \\
\text { tir os fenôme- } \\
\text { nos cotidia- } \\
\text { nos, oferecem } \\
\text { contexto ao } \\
\text { aluno e ao } \\
\text { professor, }\end{array}$ & $\begin{array}{l}\text { A Primeira } \\
\text { Lei de New- } \\
\text { ton do Movi- } \\
\text { mento - Inér- } \\
\text { cia. Cap. 2, p. } \\
44 \text { - 59; } \\
\text { A Segunda } \\
\text { Lei de New- } \\
\text { ton do Movi- } \\
\text { mento. Cap. 4, } \\
\text { p. } 73 \text { - 84; } \\
\text { A Terceira Lei } \\
\text { de Newton do } \\
\text { Movimento. } \\
\text { Cap. 5, p. } 85 \text { - }\end{array}$ \\
\hline
\end{tabular}




\begin{tabular}{|c|c|c|c|c|c|}
\hline & $\begin{array}{l}276-299 ; \\
\text { Os textos assu- } \\
\text { mem um discur- } \\
\text { so de verdades } \\
\text { prontas, não } \\
\text { abrindo reflexões } \\
\text { para possíveis } \\
\text { controvérsias. }\end{array}$ & $\begin{array}{l}\text { mem um discurso } \\
\text { de verdades } \\
\text { prontas, embora } \\
\text { apresente contex- } \\
\text { tualização e apli- } \\
\text { cação cotidiana, } \\
\text { ainda que não } \\
\text { abra reflexão } \\
\text { para possíveis } \\
\text { controvérsias. }\end{array}$ & $\begin{array}{l}\text { Os textos inter- } \\
\text { calam discursos } \\
\text { de verdades } \\
\text { prontas com } \\
\text { discussões con- } \\
\text { textualizadas e } \\
\text { aplicação coti- } \\
\text { diana. }\end{array}$ & $\begin{array}{l}\text { analisando a } \\
\text { aplicação das } \\
\text { leis de New- } \\
\text { ton; } \\
\text { O texto tem o } \\
\text { formato de } \\
\text { apresentação } \\
\text { que difere dos } \\
\text { demais, discu- } \\
\text { tindo a con- } \\
\text { servação dos } \\
\text { momentos } \\
\text { linear e angu- } \\
\text { lar antes de } \\
\text { apresentar as } \\
\text { leis de New- } \\
\text { ton. }\end{array}$ & $\begin{array}{l}98 ; \\
\text { Momentum. } \\
\text { Cap. 6, p. } 99 \text { - } \\
\text { 103; } \\
\text { Movimento de } \\
\text { Rotação. Cap. } \\
\text { 8, p. } 132 \text { - } \\
155 ; \\
\text { O texto tem o } \\
\text { formato de } \\
\text { apresentação } \\
\text { com pouca } \\
\text { variação em } \\
\text { relação aos } \\
\text { demais, dife- } \\
\text { rindo em } \\
\text { relação ao uso } \\
\text { da matemáti- } \\
\text { ca. }\end{array}$ \\
\hline $\begin{array}{l}\text { Apresentação } \\
\text { das leis de New- } \\
\text { ton }\end{array}$ & $\begin{array}{l}\text { As leis são apre- } \\
\text { sentadas no } \\
\text { início do texto, } \\
\text { como axiomas } \\
\text { (p. 76). Não há } \\
\text { construção das } \\
\text { leis. }\end{array}$ & $\begin{array}{l}\text { As leis são cons- } \\
\text { truídas ao longo } \\
\text { dos textos, em- } \\
\text { bora sem discutir } \\
\text { profundamente } \\
\text { suas bases, de } \\
\text { forma linear, sem } \\
\text { historicidade. }\end{array}$ & $\begin{array}{l}\text { Abre o capítulo } \\
\text { dizendo que as } \\
\text { três leis funda- } \\
\text { mentais do } \\
\text { movimento são } \\
\text { baseadas em } \\
\text { observações } \\
\text { experimentais e } \\
\text { formuladas por } \\
\text { Newton (p. } \\
\text { 108); } \\
\text { As leis são } \\
\text { construídas ao } \\
\text { longo do texto, } \\
\text { embora sem } \\
\text { discutir profun- } \\
\text { damente suas } \\
\text { bases, e com } \\
\text { historicidade } \\
\text { linear, de Gali- } \\
\text { leu a Newton. }\end{array}$ & $\begin{array}{l}\text { As leis são } \\
\text { apresentadas e } \\
\text { discutidas } \\
\text { buscando } \\
\text { abranger fe- } \\
\text { nômenos } \\
\text { cotidianos, } \\
\text { sem nenhuma } \\
\text { historicidade. }\end{array}$ & $\begin{array}{l}\text { As leis são } \\
\text { apresentadas } \\
\text { buscando } \\
\text { abranger fe- } \\
\text { nômenos } \\
\text { cotidianos, } \\
\text { apresentando } \\
\text { alguma histo- } \\
\text { ricidade, em- } \\
\text { bora linear, de } \\
\text { Aristóteles a } \\
\text { Galileu e } \\
\text { Copérnico, e } \\
\text { de ambos a } \\
\text { Newton. }\end{array}$ \\
\hline $\begin{array}{l}\text { Enfoques e con- } \\
\text { textualização }\end{array}$ & $\begin{array}{l}\text { Os exemplos e } \\
\text { exercícios apre- } \\
\text { sentados não são } \\
\text { contextualizados } \\
\text { ao Brasil: astro- } \\
\text { nautas e fogue- } \\
\text { tes, trenó e } \\
\text { campo de gelo; } \\
\text { exercícios base- } \\
\text { ados em diagra- } \\
\text { mas de força em } \\
\text { bloquinhos; } \\
\text { Utiliza "fogue- } \\
\text { tes" como "um }\end{array}$ & $\begin{array}{l}\text { Os exercícios } \\
\text { possuem enunci- } \\
\text { ados contextuali- } \\
\text { zados, mas com a } \\
\text { maioria voltada } \\
\text { para diagrama de } \\
\text { forças em blo- } \\
\text { quinhos; } \\
\text { Alterna, ao longo } \\
\text { do texto, alguns } \\
\text { exemplos contex- } \\
\text { tualizados, outros } \\
\text { idealizados. }\end{array}$ & $\begin{array}{l}\text { Discute aplica- } \\
\text { ção das leis de } \\
\text { Newton com } \\
\text { bloquinhos, } \\
\text { trenó de gelo, } \\
\text { elevador, má- } \\
\text { quina de Atwo- } \\
\text { od, semáforo } \\
\text { suspenso, fo- } \\
\text { guete espacial, } \\
\text { etc; } \\
\text { Exemplifica a } \\
\text { terceira lei com } \\
\text { noções cotidia- }\end{array}$ & $\begin{array}{l}\text { O livro apre- } \\
\text { senta um } \\
\text { enfoque inter- } \\
\text { ligando ciên- } \\
\text { cia, tecnologia } \\
\text { e aplicações } \\
\text { sociais. Por } \\
\text { ser o único } \\
\text { material brasi- } \\
\text { leiro analisa- } \\
\text { do, se destaca } \\
\text { quanto aos } \\
\text { outros por } \\
\text { apresentar }\end{array}$ & $\begin{array}{l}\text { Os textos } \\
\text { buscam discu- } \\
\text { tir os fenôme- } \\
\text { nos cotidia- } \\
\text { nos, analisan- } \\
\text { do a aplicação } \\
\text { das leis de } \\
\text { Newton. Ape- } \\
\text { sar de ser } \\
\text { estrangeiro, o } \\
\text { livro discute } \\
\text { questões do } \\
\text { dia a dia, } \\
\text { entrando fa- }\end{array}$ \\
\hline
\end{tabular}




\begin{tabular}{|l|l|l|l|l|l|}
\hline & $\begin{array}{l}\text { exemplo notável } \\
\text { do efeito da } \\
\text { conservação do } \\
\text { momento" (p. } \\
223) .\end{array}$ & & $\begin{array}{l}\text { nas, como chu- } \\
\text { tar uma bola, } \\
\text { dar um soco etc; }\end{array}$ & $\begin{array}{l}\text { exemplos e } \\
\text { exercícios } \\
\text { dentro do } \\
\text { nosso contex- } \\
\text { to. }\end{array}$ & $\begin{array}{l}\text { cilmente no } \\
\text { contexto dos } \\
\text { países ociden- } \\
\text { tais, como o } \\
\text { Brasil. } \\
\text { são, ex sua } \\
\text { maioria, de } \\
\text { diagrama de } \\
\text { forças. }\end{array}$ \\
\hline
\end{tabular}

Constatamos, assim, conforme Kawamura (2013) apontava, que os conteúdos são apresentados em uma ordem 'naturalizada' (no sentido de sugerir que a ordenação dos saberes físicos deva ser feita de uma única maneira) - o que nos remete às influências das primeiras obras didáticas francesas, as quais começavam pela apresentação das leis e, somente depois, era apresentado o princípio que as fundamenta (o da conservação da quantidade de movimento) (BRAGA; GUERRA; REIS, 2008). Essa escolha é completamente diferente daquela feita por Newton que, conforme discutido anteriormente, primeiro buscou definir a quantidade de movimento a partir dos conceitos de massa e velocidade e, somente depois, formalizou suas leis, assumindo, portanto, concepções de espaço e de tempo para formalizá-las.

A estrutura e organização de conteúdo constatadas no Tipler (2000), Halliday, Resnick e Walker (2008), e Serway e Jewett (2009), apresentam pouco destaque à discussão epistemológica, uma vez que, nesses três livros, a maioria dos conceitos é apresentada de forma 'pronta', como 'verdades absolutas', havendo pouca ou nenhuma contextualização e aplicação cotidiana à cultura brasileira. O livro do Tipler (2000) apresenta as leis de Newton como axiomas, em quadros presentes logo no início do capítulo. Assim, não há discussão prévia sobre o processo de formulação. Halliday, Resnick e Walker (2008) buscam construir as leis ao longo do texto, a partir de exemplos idealizados, como o movimento de corpos, desprezando-se as forças resistivas, sem, no entanto, abordar quaisquer problemáticas históricas. O processo de construção das leis de Newton, em Serway e Jewett (2009), é apresentado com uma historicidade linear, partindo dos experimentos idealizados por Galileu, como o da pista sem atrito, chegando até Newton e a formalização de suas leis. Ao fazer isso, o livro distancia-se da complexidade e das idas e vindas do processo de construção do conhecimento.

Hewitt (2002), reconhecido como um livro de enfoque em discussões conceituais e pouca abordagem matemática, pouco diferiu dos três primeiros livros anteriormente comentados. Sua estrutura e organização de conteúdos são bastante parecidas com os demais, sendo as leis de Newton apresentadas sem as concepções que as fundamentam, inclusive de estética e de simetria.

Por fim, o GREF (2012) foi o único dos livros analisados que não apresentou a estrutura e organização de conteúdo de forma semelhante aos demais. A obra inicia-se construindo os conceitos de conservação de movimento e, a partir deles, apresenta a formulação das leis. O caminho adotado parece convergir com o processo de construção das leis na filosofia newtoniana, ainda que não siga, com exatidão, a mesma progressão do Principia na construção 
das leis, do ponto de vista histórico. O livro, no entanto, não apresenta discussões profundas acerca dos conceitos estéticos e simétricos que possam estar presentes nas bases das leis. Seu enfoque está nas relações de ciência, tecnologia e aplicações na sociedade.

Conhecidas as estruturas e enfoques de cada livro, faremos, a seguir, uma análise comparativa entre eles, observando, de forma mais amiúde, os principais conceitos mecânicos que compõem a filosofia newtoniana do movimento, à luz da concepção de estética e de simetria adotadas neste trabalho, bem como sua aproximação ou distanciamento daquilo que Newton propôs originalmente.

\section{A análise dos conceitos}

O quadro 4, a seguir, apresenta a sistematização dos conceitos físicos analisados nesse trabalho, na concepção de Isaac Newton, conforme fontes secundárias históricas e historiográficas, de Menezes e de nossas inferências. A partir dessa sistematização, discutiremos como esses conceitos são apresentados nos livros analisados.

Quadro 4 - Conceitos físicos segundo Newton, Menezes e nossas inferências.

\begin{tabular}{|c|c|c|c|}
\hline $\begin{array}{l}\text { Conceitos } \\
\text { físicos }\end{array}$ & Segundo Newton & Segundo Menezes & Nossas inferências \\
\hline Inércia & $\begin{array}{l}\text { Tida como uma "força inata da maté- } \\
\text { ria", é um poder de resistir mediante } \\
\text { o qual todo e qualquer corpo, haja o } \\
\text { que houver nele, permanece em seu } \\
\text { estado atual, seja de repouso ou de } \\
\text { movimento uniforme em linha reta. }\end{array}$ & $\begin{array}{l}\text { Condição da manutenção } \\
\text { do movimento de um } \\
\text { corpo, dada pela manuten- } \\
\text { ção das simetrias espaci- } \\
\text { ais. }\end{array}$ & $\begin{array}{l}\text { Manutenção do estado de } \\
\text { movimento de um corpo, } \\
\text { dada pela manutenção das } \\
\text { simetrias espaciais. }\end{array}$ \\
\hline Espaço & $\begin{array}{l}\text { Absoluto, vazio, infinito e homogê- } \\
\text { neo, sem apresentar um centro defi- } \\
\text { nido para o Universo, tampouco } \\
\text { limitar direções específicas para o } \\
\text { movimento dos corpos. Considera o } \\
\text { espaço relativo, que os nossos senti- } \\
\text { dos determinam. }\end{array}$ & $\begin{array}{l}\text { Em termos ideais, é simé- } \\
\text { trico (homogêneo e isotró- } \\
\text { pico). }\end{array}$ & $\begin{array}{l}\text { Homogêneo e isotrópico, } \\
\text { tendo suas simetrias revela- } \\
\text { das pela interpretação hu- } \\
\text { mana do movimento da } \\
\text { matéria. }\end{array}$ \\
\hline Tempo & $\begin{array}{l}\text { O tempo absoluto, real e matemático, } \\
\text { por si só e por sua natureza flui uni- } \\
\text { formemente. O tempo relativo, apa- } \\
\text { rente e comum é uma medida sensí- } \\
\text { vel e externa da duração por meio do } \\
\text { movimento. }\end{array}$ & $\begin{array}{l}\text { Simétrico, no sentido de } \\
\text { que flui uniformemente; } \\
\text { assimétrico, posto que é } \\
\text { irreversível, flui em uma } \\
\text { só direção }\end{array}$ & $\begin{array}{l}\text { Simétrico, no sentido de que } \\
\text { flui uniformemente, em } \\
\text { intervalos sempre iguais; } \\
\text { assimétrico, posto que é } \\
\text { irreversível e flui numa só } \\
\text { direção. }\end{array}$ \\
\hline Força & $\begin{array}{l}\text { É apresentada em suas definições } \\
\text { como uma ação exercida sobre um } \\
\text { corpo para modificar seu estado, seja } \\
\text { de repouso, seja de movimento uni- } \\
\text { forme em linha reta. Aconteceria por } \\
\text { contato ou à distância, ou ainda seria } \\
\text { centrípeta. Conceito chave da filoso- } \\
\text { fia newtoniana para a análise da }\end{array}$ & $\begin{array}{l}\text { Agente que quebra a sime- } \\
\text { tria no movimento transla- } \\
\text { cional. Para isso, deve } \\
\text { atuar como agente externo } \\
\text { do sistema. }\end{array}$ & $\begin{array}{l}\text { Encontra suas bases na } \\
\text { modificação da quantidade } \\
\text { de movimento translacional } \\
\text { em função do tempo. Para } \\
\text { que haja modificação da } \\
\text { quantidade de movimento } \\
\text { de um sistema, deve haver }\end{array}$ \\
\hline
\end{tabular}




\begin{tabular}{|c|c|c|c|}
\hline & quantidade de movimento. & & atuação de forças externas. \\
\hline Torque & $\begin{array}{l}\text { Não foi abordado nas obras pesqui- } \\
\text { sadas para esse trabalho. }\end{array}$ & $\begin{array}{l}\text { Agente que quebra a sime- } \\
\text { tria no movimento rotaci- } \\
\text { onal. Para isso, deve atuar } \\
\text { como agente externo do } \\
\text { sistema. }\end{array}$ & $\begin{array}{l}\text { Encontra suas bases na } \\
\text { modificação da quantidade } \\
\text { de movimento rotacional } \\
\text { em função do tempo. Para } \\
\text { que haja modificação da } \\
\text { quantidade de movimento } \\
\text { rotacional de um sistema, } \\
\text { deve haver atuação de for- } \\
\text { ças externas. }\end{array}$ \\
\hline Massa & $\begin{array}{l}\text { Provinda da densidade e da grandeza } \\
\text { (volume) dos corpos, tomadas em } \\
\text { conjunto. É uma quantidade física } \\
\text { inerente à natureza dos corpos mate- } \\
\text { riais, que se mantém inalterada ao } \\
\text { longo de todas as mudanças de mo- } \\
\text { vimento. Considerou a massa para a } \\
\text { quantificação do movimento. }\end{array}$ & $\begin{array}{l}\text { Quantifica a dificuldade de } \\
\text { se modificar a quantidade } \\
\text { de movimento de um cor- } \\
\text { po. }\end{array}$ & $\begin{array}{l}\text { Além da quantidade de } \\
\text { matéria, a massa define a } \\
\text { dificuldade de se alterar o } \\
\text { estado de movimento }\end{array}$ \\
\hline $\begin{array}{l}\text { Plano de } \\
\text { referência }\end{array}$ & $\begin{array}{l}\text { Utilizado, a partir da compreensão da } \\
\text { obra de Descartes, para relacionar } \\
\text { entidades físicas a fim de quantificar } \\
\text { o movimento. }\end{array}$ & $\begin{array}{l}\text { Quebra a simetria do espa- } \\
\text { ço ao permitir expressar } \\
\text { numericamente diferentes } \\
\text { posições de um e de outro } \\
\text { corpo em função dessa } \\
\text { referência. }\end{array}$ & $\begin{array}{l}\text { De natureza essencialmente } \\
\text { humana, em termos de for- } \\
\text { mato e posição, é um agente } \\
\text { que quebra a simetria espa- } \\
\text { cial, ao permitir expressar } \\
\text { numericamente diferentes } \\
\text { posições dos corpos. }\end{array}$ \\
\hline $\begin{array}{l}\text { Primeira } \\
\text { lei }\end{array}$ & $\begin{array}{l}\text { Axioma, que tem a função de uma } \\
\text { definição daquilo que é considerado } \\
\text { o "movimento de referência". Assim, } \\
\text { os movimentos (ou repouso) que } \\
\text { obedecem a essa lei não precisam de } \\
\text { explicação, enquanto os que não } \\
\text { obedecem precisam. }\end{array}$ & $\begin{array}{l}\text { Manutenção do estado de } \\
\text { movimento de um corpo. } \\
\text { Isso significa a permanên- } \\
\text { cia em repouso do que } \\
\text { estiver em repouso, ou a } \\
\text { manutenção da direção e } \\
\text { do valor da velocidade do } \\
\text { que estiver se movendo. }\end{array}$ & $\begin{array}{l}\text { Manutenção da homogenei- } \\
\text { dade e da simetria do espa- } \\
\text { ço, resultando na manuten- } \\
\text { ção do estado de movimento } \\
\text { de um corpo. }\end{array}$ \\
\hline $\begin{array}{l}\text { Segunda } \\
\text { lei }\end{array}$ & $\begin{array}{l}\text { Apresenta a atividade de corpos em } \\
\text { movimentos não inerciais, quando a } \\
\text { resultante das forças que agem sobre } \\
\text { um corpo não for considerada nula. } \\
\text { Qualquer força gera um movimento } \\
\text { que é sempre dirigido no mesmo } \\
\text { sentido da força geradora, e pode ser } \\
\text { composto pela atuação de mais de } \\
\text { uma força. }\end{array}$ & $\begin{array}{l}\text { A aplicação de uma força } \\
\text { externa pode causar a } \\
\text { modificação do estado de } \\
\text { movimento de um corpo. } \\
\text { A quantidade de movi- } \\
\text { mento alterada possui um } \\
\text { valor relativo, que depen- } \\
\text { de do observador. Isso } \\
\text { significaria uma alteração } \\
\text { local da simetria do espaço } \\
\text { em que se realiza o movi- } \\
\text { mento. }\end{array}$ & $\begin{array}{l}\text { Quebra da homogeneidade } \\
\text { ou da isotropia (ou de am- } \\
\text { bas) do espaço, resultando } \\
\text { na modificação da quanti- } \\
\text { dade de movimento de um } \\
\text { sistema ou de sistemas. }\end{array}$ \\
\hline $\begin{array}{l}\text { Terceira } \\
\text { lei }\end{array}$ & $\begin{array}{l}\text { Quando um corpo se choca com } \\
\text { outro, e por sua força altera o movi- } \\
\text { mento do outro, esse corpo, também } \\
\text { sofre uma variação idêntica em seu } \\
\text { movimento, em direção à parte con- } \\
\text { trária. As variações causadas por } \\
\text { essas ações são iguais, não nas velo- } \\
\text { cidades, mas no movimento dos } \\
\text { corpos, isto é, se os corpos não forem }\end{array}$ & $\begin{array}{l}\text { Estabelece a impossibili- } \\
\text { dade de se gerar movimen- } \\
\text { to em apenas um único } \\
\text { corpo, de modo a manter a } \\
\text { homogeneidade e a isotro- } \\
\text { pia do espaço. Sendo as- } \\
\text { sim, é o movimento da } \\
\text { matéria que revela a sime- } \\
\text { tria do espaço. }\end{array}$ & $\begin{array}{l}\text { Princípio de que nenhum } \\
\text { movimento pode acontecer } \\
\text { isoladamente, ou seja, todo } \\
\text { movimento deve ser a inte- } \\
\text { ração de duas partes, a fim } \\
\text { de manter as simetrias espa- } \\
\text { ciais. }\end{array}$ \\
\hline
\end{tabular}




\begin{tabular}{|l|l|l|l|}
\hline impedidos por outros empecilhos. & & \\
Isso porque, visto que os movimentos & & & \\
são igualmente modificados, as vari- & ações das velocidades feitas em dire- \\
ção às suas partes contrárias são & & & \\
inversamente proporcionais aos cor- & & & \\
pos. Também se dá nas atrações. & & \\
\hline
\end{tabular}

Ao discutirem o conceito de inércia, Tipler (2000) e Hewitt (2002) atribuem a Newton a ideia de manutenção ou resistência de alteração do movimento sem, no entanto, relacionar o conceito à atuação ou à ausência de uma força. Serway e Jewett (2009), por sua vez, estabelecem que a inércia está associada às situações sob a ausência de uma força. Halliday, Resnick e Walker (2009) partem do conceito de ímpeto para discutir a natureza da inércia, baseando-se num experimento idealizado por Galileu. O GREF (2012) não faz discussão do conceito de forma isolada, discutindo-o de forma integrada à primeira lei de Newton.

Força e torque são, segundo Menezes (2005), agentes que quebram a simetria do movimento linear e rotacional, respectivamente, e, para isso, precisam, necessariamente, atuar como agentes externos ao sistema. Em nossa pesquisa, constatamos que todos os livros mostram a força como responsável por modificar a quantidade de movimento linear. Entretanto, as interpretações de Hewitt (2002) e de Halliday, Resnick e Walker (2009) para força mostram-na como um empurrão ou puxão e, neste sentido, vão, aparentemente, ao encontro à ideia inicial intuitiva de Newton, proposta por Jammer (1979), mas de forma limitada, sem ampliá-la e/ou discuti-la.

Os cinco livros analisados parecem convergir para a ideia newtoniana de força e torque como analogias ou interpretações de agentes que modificam a quantidade de movimento. Entretanto, com exceção do GREF (2012), todos colocam o conceito de força e sua inequívoca associação com mudança de movimento como algo periférico, quase um adendo dentro de um novo conceito chamado de 'impulso' (que consiste na variação quantitativa da quantidade de movimento dividida pelo intervalo de tempo).

Constatamos, também, que prevalece, de modo muito mais forte, a relação $\vec{F}=m \vec{a}$, como se fosse proposta por Newton - e que, conforme mostramos, surgiu apenas em 1747, 20 anos depois de sua morte. Não há, em nenhuma obra, a discussão da importância de força e torque como agentes da quebra de simetria em um sistema ou em um movimento.

Os livros, de forma geral, apresentam as discussões acerca da quantidade de movimento linear, ou momento linear, partindo da definição matemática $\vec{p}=m \vec{v}$, (ou $\vec{Q}=m \vec{v}$, , no caso do GREF (2012)). Todos ressaltam que a quantidade de movimento linear se conserva, e que este é um dos princípios fundamentais da física. Apesar da naturalização na escolha da sequência para apresentar os conceitos, Serway e Jewett (2009) discutem-no como uma distinção quantitativa do movimento de dois corpos com velocidades iguais e massas distintas. $\mathrm{O}$ GREF (2012) também argumenta que a ideia de quantificação do movimento advém da análise de interações entre dois objetos com velocidades iguais e massas diferentes. $\mathrm{O}$ fato de atri- 
buir a construção do conceito a uma análise, de natureza humana, reforça um certo caráter estético. Diferentemente, Hewitt (2002) não discute o papel do ser humano na análise das interações e afirma que quantidade de movimento é uma propriedade das coisas que se movem, o que nos parece atribuir uma existência do conceito inerente à natureza do movimento, independentemente da interpretação humana e dos significados atribuídos.

Todos os livros afirmam que a quantidade de movimento pode ser alterada pela atuação de uma força externa. Nesse sentido, Hewitt (2002) apresenta uma relação entre a atuação de uma força e a modificação na quantidade de movimento, de maneira muito próxima da relação que Westfall (1984 apud NEVES, 2000) atribuiu a Newton. Ao relacionar as grandezas, Hewitt (2002) escreveu F.t $=\Delta(m v)$; enquanto Westfall (1984 apud NEVES, 2000) argumenta que Newton escrevia $F=\Delta m v$.

Os livros não discutem as propriedades do espaço para fundamentar a conservação do movimento, nem do tempo para fundamentar os pressupostos definidos por Newton (adota-se a passagem do tempo como algo já naturalizado dentro da mecânica clássica). Não é sequer citada, em nenhum dos livros, a homogeneidade do espaço - simetria que implica na conservação do estado de movimento de qualquer corpo e que estabelece as leis de Newton no movimento translacional (de acordo com Menezes e Prigogine).

Como ressaltado por Martins (2012), a primeira lei descreve situações em que os corpos estão livres de forças impressas. Halliday, Resnick e Walker (2008), e Serway e Jewett (2009) utilizam essa mesma linha de argumento, definindo a lei como a ausência de atuação de forças externas. Serway e Jewett (2009, p. 112), inclusive, explicitam que "a primeira lei de Newton não diz o que acontece para um corpo com força resultante nula, isto é, várias forças que se cancelam". Entretanto, em Hewitt (2002) encontramos uma associação do estado de inércia aos corpos em que as forças atuantes equilibram-se. Parece-nos um erro de interpretação quanto à definição da primeira lei de Newton, uma vez que ela estabelece como se comporta um movimento na ausência de forças. O GREF (2012), inicialmente, associa a primeira lei de Newton à conservação da quantidade de movimento e assume que sua principal função é definir os 'referenciais inerciais'. Isso parece ir plenamente ao encontro da definição de Martins (2012, p. 6), já que argumenta ser a primeira lei um axioma que "tem a função de uma definição daquilo que é considerado o movimento de referência da mecânica newtoniana”. Não há discussão das propriedades absolutas do espaço newtoniano, como a homogeneidade e a isotropia - algo que implicaria no fato de um movimento inerte não possuir razão para alterar esse estado, ou seja, manteria a simetria do movimento.

Sobre a segunda lei, Halliday, Resnick e Walker (2008), GREF (2012) e Hewitt (2002) assumem-na como uma alteração na quantidade de movimento entre partes de um sistema. No entanto, Tipler (2000) e Hewitt (2002) não argumentam que, para modificar a quantidade de movimento de um sistema, é necessária a atuação de forças externas. Tipler (2000) apenas argumenta que a modificação da quantidade de movimento verifica-se experimentalmente, sem dizer como fazê-lo. Halliday, Resnick e Walker (2008) afirmam que Newton ex- 
pressou a segunda lei, originalmente, em termos do momento, e apresenta a relação de força como derivada da quantidade de movimento em função do tempo: $\sum \vec{F}=d \vec{p} / d t=$ $m . d \vec{v} / d t \Rightarrow \vec{F}=m \vec{a}$. Serway e Jewett (2009) seguem a mesma linha, apresentam as mesmas relações para o conceito de força e estabelecem que $\vec{F}=m \vec{a}$ é boa aproximação com partículas em que a massa permanece constante. Apenas GREF (2012) não apresenta prioritariamente a relação $\sum \vec{F}=\vec{F}_{R E S}=m \vec{a}$ (a somatória das forças externas atuantes é igual à força resultante, que é igual ao produto da massa pela aceleração). A obra apresenta a força como variação da quantidade de movimento, afirmando categoricamente: "assim escrevemos que $\Delta Q=F . \Delta t$. A partir do desenvolvimento da segunda igualdade da expressão acima, pudemos compreender que $\Delta Q=F . \Delta t$ equivale a $F=m . a$, que é a expressão 'mais conhecida' que corresponde à segunda lei de Newton" (GREF, 2012, p. 44). Dessa forma, o livro enuncia a segunda lei de Newton de forma similar à apresentada neste trabalho, ou seja, é a força que causa a variação da quantidade de movimento por unidade de tempo (GREF (2012). Não há discussões acerca das interpretações e definições newtonianas que fundamentam as forças como elementos que evidenciam as alterações locais da simetria do espaço em que o movimento é realizado.

Como escreveu Menezes (2005, p. 43), a terceira lei de Newton "implica a impossibilidade de se gerar movimento, seja de rotação ou de translação, em um único objeto, sendo inevitável gerar, em pelo menos dois objetos, movimentos opostos". Nesse sentido, ainda que não façam referência às propriedades do espaço que fundamentam essa impossibilidade, nem discutam profundamente a afirmação contida na lei, todos os livros concordam que as forças se manifestam em pares e que acontecem de forma simultânea. Serway e Jewett (2009, p. 118) e Hewitt (2002, p. 87) são mais incisivos e afirmam que uma força isolada não pode existir. Contudo, não associam à homogeneidade do espaço. A discussão dessas questões não aparece em nenhum livro, apesar de o $\operatorname{GREF}(2012$, p. 46) terminar a discussão da terceira lei com a seguinte frase: "Dessa forma, podemos compreender como uma força pode alterar a quantidade de movimento de uma parte e, no conjunto, manter-se invariante a quantidade de movimento do sistema como um todo". Em suma, parece estar um pouco mais preocupado em associar uma simetria a esta lei.

\section{Considerações finais}

Este trabalho aponta que, embora não haja consenso sobre as concepções de estética e de simetria, sua importância na formulação atual dos princípios fundantes da física é inquestionável e bastante forte, haja vista a sua presença na conservação dos princípios da física. No que tange às leis de Newton, a discussão de estética e de simetria oferece contribuições relevantes e centrais para que sejam bem compreendidas, ainda que as concepções acerca desses conceitos apresentem enfoques um pouco diferentes entre as diferentes épocas. Uma concepção contemporânea, principalmente a partir de Menezes e Prigogine, é, de maneira geral, permeada pelo mesmo contexto histórico da prática de formação de professores de nossa épo- 
ca e pode ser observada nas reflexões conceituais das leis de Newton, importantes para o ensino da física. Portanto, essa discussão pode agregar discussões epistemológicas e oferecer uma contextualização para a compreensão desses conceitos. Todavia, notamos que há omissão desta discussão nos livros didáticos de ensino superior usados em licenciaturas.

Sabemos que não é neutro, tampouco simples, o processo de transposição da construção de um conhecimento físico para um formato epistemológico que possa ser organizado em livros didáticos e que apresente as discussões das bases que fundamentam tal conhecimento, ou seja, o processo não depende apenas das ciências de referência, mas recebe influências de outros fatores, como as intervenções de elites intelectuais e do poder político institucional (CHEVALLARD, 1991). No caso do objeto de estudo deste trabalho, a nosso ver, essa transposição parece trazer mais prejuízos do que avanços para a compreensão das leis de Newton, sobretudo no que tange aos elementos essencialmente humanos de seus conceitos. Isso porque a discussão de estética e de simetria é capaz de revelar mais explicitamente, por exemplo, as arbitrariedades humanas presentes nos modelos, incluindo seus ideais de perfeições estética, suas simetrias idealizadas e o quanto a realidade observada pode ser diferente desses modelos. Com isso, acreditamos colocar o ser humano no ponto central da construção do conhecimento, posto que tanto a estética adotada quanto a simetria enxergada em cada fenômeno advêm dele.

Além disso, colocamos em questão as dúvidas sobre os princípios mais fundamentais da física. Trata-se de uma mudança radical, que muda a costumeira maneira de priorizar o ensino de um determinado conceito, como se ele tivesse uma existência por si mesmo, desprovido de humanidade - como se fosse intrínseco à natureza e/ou já acabado. Talvez por isso, o percurso da ciência possui um forte componente estético, que se modifica juntamente com o ser humano.

Por isso, sugerimos maior presença desta abordagem no ensino de física, notadamente no ensino das três leis de Newton, em especial nos cursos de formação de professores de física. É preciso que se evite a naturalização dos conteúdos e estruturas curriculares, de forma a não ser criado um modelo de ensino imutável e que não considera a complexidade e o papel das escolhas estéticas do ser humano na construção do conhecimento físico. Pensar num curso de formação de professores e em livros didáticos em que a abordagem se daria pelas bases estéticas e simétricas da física poderia ressignificar os conhecimentos e acabaria por proporcionar inovações curriculares que parecem re-humanizar esses conhecimentos e, por isso mesmo, favoreceria uma reflexão mais profunda acerca dos fenômenos físicos.

Nesse sentido, este trabalho busca oferecer uma contribuição para esta discussão, a qual acreditamos mereça receber diferentes olhares e reflexões, de uma maneira geral, não apenas por ser inovadora, mas por conter, em sua essência, as bases ontológicas e epistemológicas fundamentais de qualquer ciência. 


\section{Referências}

ABRAPEC. Associação Brasileira de Pesquisa em Educação em Ciências. Encontro Nacional de Pesquisa em Educação em Ciências (ENPEC). ENPECs edições anteriores. 2015. Disponível em: $<$ http://www.abrapec.ufsc.br/enpecs-anteriores/>. Acesso em: 02 jul. 2016.

AURÉLIO. Dicionário do Aurélio. Disponível em: <https://dicionariodoaurelio.com/>. Acesso em: 17 mai. 2018.

AZANHA, J. M. P. Uma ideia de pesquisa educacional. 2. ed. São Paulo: Edusp. 208p.

BRAGA, M.; GUERRA, A.; REIS, J. C. O papel dos livros didáticos franceses do Século XIX na construção de uma concepção dogmático-instrumental do ensino de física. Caderno Brasileiro de Ensino de Física, v. 25, n. 3, p. 507-522, dez. 2008.

BRASIL. Ministério da Educação. Parâmetros Curriculares Nacionais (Ensino Médio). Secretaria de Educação Média e Tecnológica. Brasília: MEC, 2000.

BRASIL. Secretaria de Educação Média: Parâmetros Curriculares Nacionais + - Ensino Médio: Orientações Educacionais Complementares aos Parâmetros Curriculares Nacionais. Física. Secretaria de Educação Média. Brasília: MEC - SEMTEC, 2002.

BUENO, S. Grande dicionário etimológico prosódico da língua portuguesa. São Paulo: Edição Saraiva, 1965. 3 v.

CAPES. Banco de Teses e Dissertações. Disponível em: $<$ http://bancodeteses.capes.gov.br/banco-teses/\#/>. Acesso em: 30 set. 2016.

CHEVALLARD, Y. La transposición didáctica: del saber sabio al saber enseñado. Buenos Aires: Aique, 1991.

COHEN, B.; WESTFALL R. S. Newton: textos, antecedentes, comentários. Tradução: Vera Ribeiro. Rio de Janeiro: Contraponto/EDUERJ, 2002.

DICIO. Dicio Online de Português. Disponível em: <https://www.dicio.com.br/>. Acesso em: 17 mai. 2018.

FAPESP. Biblioteca Virtual. Banco de dados. Disponível em: <http://www.bv.fapesp.br/pt/assunto/2016/banco-de-dados/>. Acesso em: 30 set. 2016.

FORATO, T. C. M. Isaac Newton, as profecias bíblicas e a existência de Deus. In: SILVA, C. C. (Org.) Estudo de História e Filosofia das Ciências: subsídios para aplicação no ensino. São Paulo: Livraria da Física. 2006. p. 191-206. 
FORATO, T. C. M. A Filosofia Mística e a Doutrina Newtoniana: uma discussão historiográfica. Alexandria Revista de Educação em Ciência e Tecnologia, v. 1, n. 3, p. 29-53, nov. 2008.

FORATO, T. C. M.; PIETROCOLA, M.; MARTINS, R. A. História da ciência e religião: uma proposta para discutir a natureza da Ciência. In: SIMPÓSIO NACIONAL DE ENSINO DE FÍSICA, XVII, 2007, São Luiz, MA. Atas...

FORATO, T. C. M.; PIETROCOLA, M.; MARTINS, R. A. Historiografia e natureza da ciência em sala de aula. Caderno Brasileiro de Ensino de Física, v. 28, n. 1, p. 27-59, 2011.

GARCIA, M. N. Livros didáticos de física e de ciências: contribuições da pesquisa para o ensino. Educar em Revista, n. 44, p. 145-163, 2012.

GRUPO DE REELABORAÇÃO DO ENSINO DE FÍSICA. Física 1: Mecânica / GREF - 5. ed. São Paulo: Editora da Universidade de São Paulo, 2012.

HALLIDAY, D.; RESNICK, R.; WALKER, J. Fundamentos da Física - Mecânica. 8. ed. Rio de Janeiro: Livros Técnicos e Científicos Editora S. A., 2008. v. 1.

HEGEL, G.W. F. Curso de estética: o belo na arte. São Paulo: Martins Fontes, 1996.

HEWITT, P. G. Física conceitual. 9. ed. Porto Alegre: Bookman, 2002.

KANT, I. Crítica da faculdade do juízo. Rio de Janeiro: Forense Universitária, 1993.

KAWAMURA, M. R. Formação inicial de professores nas áreas de exatas: desafios para as questões de sempre. In: SILVA, J. A.; KLUTH, V. S. (Orgs). Aproximações e distanciamentos no Ensino de Ciências e Matemática: questões de identidade da área no âmbito filosófico e institucional. São Paulo: Porto de Ideias, 2013. p. 45-67.

KIRCHOF, E. R. A estética antes da estética: de Platão, Aristóteles, Agostinho, Aquino, e Locke a Baumgarten. 1. ed. Canoas: Editora da Ulbra, 2003. v. 1. 160p.

LEITE, C.; HOSOUME, Y. Astronomia nos livros didáticos de Ciências - um panorama atual. In: SIMPÓSIO NACIONAL DE ENSINO DE FÍSICA, XVI, 2005, Rio de Janeiro. Atas...

LOPES, R. C. A. Livros Didáticos: Obstáculos ao aprendizado da ciência química. Química Nova, v. 15, n. 3, p. 254-261, 1992.

LUDWIG, A. C. W. Métodos de Pesquisa em Educação. Educação em Revista, v. 14, n. 2, p. 7-32, Jul.-Dez. 2014.

MACHADO, J. P. Dicionário Etimológico da Língua Portuguesa. 4. ed. Lisboa: Livros Horizonte, 1987. v. II. 
MARTINS, R. A. A fundamentação histórica da lei da inércia: um exemplo de conflito entre educadores e historiadores da ciência no uso da história da ciência no ensino de física. In: ENCONTRO DE PESQUISA EM ENSINO DE FÍSICA, XIV, 2012, Maresias.

MARTINS, R. A. Ciência versus historiografia: os diferentes níveis discursivos nas obras sobre história da ciência. In: ALFONSO-GOLDFARB, A. M.; BELTRAN, M. H. R. (Orgs). Escrevendo a História da Ciência: tendências, propostas e discussões historiográficas. São Paulo: EDUC/Livraria Editora da Física, 2004. p. 115-145.

MARTORANO, S. A. A.; MARCONDES, M. E. R. As concepções de ciência dos livros didáticos de química, dirigidos ao ensino médio, no tratamento da cinética química no período de 1929 a 2004. Investigações em Ensino de Ciências, v. 14, n. 3, p. 341-355, 2009.

MCGUIRE, J. E.; RATTANSI, P. M. Newton and the 'Pipes of Pan'. Notes \& Records. The Royal Society of London, 1966. p. 108-143.

MEGID NETO, J.; FRACAlAnZA, H. (Org.). O Livro Didático de Ciências no Brasil. 1. ed. Campinas: Editora Komedi, 2006. v. 1. 224p.

MENEZES, L. C. A Matéria uma Aventura do Espírito: fundamentos e fronteiras do conhecimento físico. 1. ed. São Paulo: Livraria da Física, 2005. 277p.

MENEZES, L. C. Simetrías, Irreversabilidad del Tiempo e Imponderabilidad en la Física. Prometeica - Revista de Filosofía y Ciencias, Córdoba, Argentina, Año II, n. 4, p. 90-91, mayo-jun. 2011.

MORAES, J. O livro didático de física e o ensino de física: suas relações e suas origens. Scientia Plena, v. 7, n. 9. 2011. Associação Sergipana de Ciência. Aracaju, 2011.

MORTIMER, E. F. Construtivismo, mudança conceitual e Ensino de Ciências: para onde vamos? Investigações em Ensino de Ciências, v. 1, n. 1, p. 20-39, 1996.

NASCIMENTO, L. F. História e natureza da ciência: um roteiro para análise do livro didático. 2011. 115 f. Dissertação (Mestrado em Ensino de Física) - Universidade Estadual da Paraíba, Campina Grande, 2011.

NEVES, M. C. D. Uma investigação sobre a natureza do movimento ou sobre uma história para a noção do conceito de força. Revista Brasileira de Ensino de Física, v. 22, n. 4, 2000.

PAGLIARINI, C. R. Uma análise da história e filosofia da ciência presente em livros didáticos de física para o ensino médio. 2007. Dissertação. (Mestrado em Física Básica) Instituto de Física de São Carlos, Universidade de São Paulo, 2007. 
PIRES, F. F.; SILVA, J. A. Estética e simetria no ensino de física: uma proposta para o ensino de mecânica. In: ENCONTRO NACIONAL DE PESQUISA EM ENSINO DE CIÊNCIAS, X, 2015, Águas de Lindoia, SP. Anais...

PRIBERAM. Dicionário Priberam da Língua Portuguesa. Disponível em: <https://www.priberam.pt/dlpo/>. Acesso em: 17 mai. 2018.

PRIGOGINE, I. O fim das certezas: tempo, caos e as leis da natureza. 1. ed. São Paulo: Editora da Universidade Estadual Paulista, 1996. 199p.

QUADROS, O. J. Estética da vida, da arte, da natureza. 2. ed. Porto Alegre. Livraria Editora Academia, 1986. 231p.

SCIELO. Scientific Electronic Library Online. Disponível em: $<$ http://www.scielo.org/php/index.php>. Acesso em: 30 set. 2016.

SBF. Sociedade Brasileira de Física. Memória. EPEF. 2015. Disponível em: $<\mathrm{http}$ //www.sbfisica.org.br/v1/index.php?option=com_content \&view=article\&id=298\&Itemi d=304>. Acesso em: 01 out. 2016.

SBF. Sociedade Brasileira de Física. Memória. SNEF. 2015. Disponível em: $<$ http://www.sbfisica.org.br/v1/index.php?option=com_content\&view=article\&id=270\&Itemi d=303>. Acesso em: 01 out. 2016.

SERWAY, R. A.; JEWETT, J. W. Jr. Princípios de física. v. 1: mecânica clássica. 3. ed. São Paulo: Cengage Learning, 2009.

SUASSUNA, A. Iniciação à estética. 9. ed. Rio de Janeiro: Editora José Olympio, 2008. 396p.

TALON-HUGON, C. A estética: histórias e teorias. Título original: L'esthétique. Coleção Biblioteca universal. 1. ed. Rio de Janeiro: Edições Texto e Grafia, 2009. 105p.

TIPLER, P. A. Física para cientistas e engenheiros - Mecânica, Oscilações e Ondas, Termodinâmica. 4. ed. Rio de Janeiro: Livros Técnicos e Científicos Editora S.A., 2000. v. 1.

WESTFALL R. S. A vida de Isaac Newton. Tradução: Vera Ribeiro. Rio de Janeiro: Nova Fronteira, 1995. 328 p.

ZYLBERSZTAJN, A. Concepções Espontâneas em Física: exemplos em dinâmica e implicações para o ensino. Revista de Ensino de Física, v. 5, n. 2, dez. 1983. 